\title{
EL SECUESTRO COMO DELITO PERMANENTE FRENTE AL DL DE AMNISTÍA
}

Juan Pablo Mañalich R. *

Introducción; 1. E1 secuestro como delito permanente; 2. E1 secuestro frente a la regulación internacional de la desaparición forzada de personas; 3. La prueba del homicidio en el proceso penal; 4. Reconocimiento de la amnistía en el proceso penal; 5. Inaplicabilidad del DL de amnistía. Dos significados de "impunidad"; 6. La amnistía como equivalente funcional de la pena. La auto-amnistía como contradicción preformativa; 7. Consecuencias para la prescripción.

\section{Introducción}

La sentencia de la Corte Suprema de 17 de noviembre de 2004, por la cual se validó la sentencia que condenó a miembros de las FF.AA. por su responsabilidad como intervinientes (autores y cómplices) en el delito de secuestro de Miguel Sandoval Rodríguez, desarrolla como razones justificativas un conjunto de consideraciones relativas a cuestiones jurídicas que han sido y siguen siendo altamente controvertidas. Es fundamental destacar el hecho de que la Corte haya fundamentado correctamente la solución de la aplicación del delito de privación de libertad ("secuestro": art. $141 \mathrm{CP}$ ) como título de incriminación, descartando el tipo privilegiado de la detención ilegal cometida por funcionario público (Art. $148 \mathrm{CP})^{1}$. La Corte acogió la tesis defendida por Bascuñán Rodríguez, en el sentido de que el tipo de la detención ilegal cometida por funcionario público debe interpretarse como un tipo privilegiado de privación de libertad, en que la razón del privilegio se encuentra en la conexión que pueda establecerse entre la actuación del funcionario y el sistema institucional de privación de libertad. Si en el hecho no se satisface esta condición, decae la razón para aplicar un tratamiento privilegiado al funcionario, a quien de este modo puede imputarse el delito común de privación de libertad. En cuanto a este punto, la sentencia de la Corte constituye un hito en la jurisprudencia penal chilena. Es el caso, sin embargo, que respecto de otras cuestiones la Corte ha acogido y desarrollado planteamientos que no pueden ser aceptados.

En este artículo me concentraré en los siguientes puntos: el secuestro como delito permanente; el secuestro frente al crimen internacional de desaparición forzada de personas; los presupuestos para la prueba del homicidio en el proceso penal; el reconocimiento procesal de la amnistía como causa de extinción de la responsabilidad penal; la posibilidad de inaplicar judicialmente el DL de amnistía, sobre la base de la consideración de la auto-amnistía como contradicción preformativa; y las consecuencias que esto podría tener para la prescripción.

\footnotetext{
* Profesor de Derecho, Universidad Adolfo Ibáñez; ayudante del Departamento de Ciencias Penales, Facultad de Derecho, Universidad de Chile.

${ }^{1}$ En el año 2003 la Corte Suprema ya había acogido esta solución, pero sin fundamentarla adecuadamente. Sobre ello, Mañalich Raffo, "Delitos contra intereses personalísimos", en 1 Revista de Derecho de la Universidad Adolfo Ibáñę: Comentario de la jurisprudencia del año 2003, Peñalolén, Viña del Mar, 2004, pp. 275-276.
} 


\section{El secuestro como delito permanente}

Probablemente la cuestión más desarrollada en la parte considerativa del fallo de casación de la Corte Suprema sea la estructura del delito de privación de libertad ("secuestro") como delito permanente. Esto impone, desde el principio, la necesidad de efectuar una clarificación. No corresponde predicar el adjetivo "permanente" respecto del sustantivo "secuestro", como frecuentemente se observa en la prensa. Pues hablar de "secuestro permanente" supone la posibilidad de hablar de "secuestro no-permanente", y éste no es el caso. El uso del adjetivo "permanente", en este contexto, tiene sentido si se predica del sustantivo "delito" (en abstracto), y se utiliza la expresión compuesta por el sustantivo y el adjetivo ("delito permanente") para definir la estructura de injusto que corresponde, entre otros delitos, al secuestro: el secuestro es un delito permanente, de modo que decir "secuestro permanente" es una redundancia.

La Corte Suprema ha respetado esta convención lingüística en su fallo de casación. Sin embargo, en su caracterización del secuestro como delito permanente, la Corte ha desarrollado esta tesis, que es correcta, atribuyéndole consecuencias que son, sin embargo, incorrectas. Esto puede mostrarse a partir de la explicación de la noción de delito permanente que ofrece la Corte:

los delitos permanentes son [...] aquellos en que el momento consumativo perdura en el tiempo. En ellos se produce también un instante en que la conducta típica está completa, pero entonces se origina un estado o situación susceptibles de ser prolongados en el tiempo, que constituyen la subsistencia de esa conducta (considerando 36).

La Corte pretende contraponer la noción de delito permanente a la noción de delito instantáneo, la cual correspondería a la siguiente descripción:

Si el delito queda consumado en un solo instante, esto es, si el proceso ejecutivo que culmina al completarse todas las exigencias del tipo delictivo se cierra en un momento determinado y único, nos encontramos en presencia de un delito instantáneo (ibid).

El problema de esta concepción de los delitos permanentes radica precisamente en su contraposición a la noción de delito instantáneo. La noción de delito permanente sólo cobra sentido si se la contrapone a la noción de delito de estado ${ }^{2}$. Aquello que según la Corte sería distintivo de los delitos instantáneos (que el delito queda consumado en un solo instante) también es predicable, sin embargo, de los delitos permanentes, así como de los delitos de estado. Pues el enunciado de que el delito queda consumado en un solo instante no es sino una consecuencia necesaria del concepto mismo de consumación: la consumación de un delito corresponde al momento en el cual se produce la completa realización del tipo (de delito en cuestión), esto es, el momento en el cual el comportamiento alcanza el estadio de ejecución en que satisface totalmente la descripción legal del hecho punible (= tipo de delito). De ahí que el concepto de consumación sea un concepto formal, que no prejuzga el grado de afectación que la completa realización del tipo representa para el objeto de protección: un delito de peligro abstracto también se

2 Así, Roxin, Derecho Penal Parte General, Civitas, Madrid, 1997, \ 10, núm. 105-107. 
REJ - Revista de Estudios de la Justicia - No 5 - Año 2004

consuma ${ }^{3}$. Ello es así tratándose de cualquier clase de delito, incluidos los delitos permanentes. Si la descripción legal del secuestro consiste en "encerrar o detener a otro privándole de su libertad" (Art. $141 \mathrm{CP}$ ), entonces esto ha de tener lugar en un momento preciso, susceptible de ser distinguido del estado de cosas previo como del estado de cosas posterior. Así, Kindhäuser:

La consumación [de la privación de libertad] se produce en el momento en que para la víctima -al menos transitoriamente- se hace imposible cambiar de ubicación por voluntad propia. La privación de libertad no requiere duración mínima, no obstante tiene que traspasarse claramente el límite de la bagatela.

La privación de libertad es un delito permanente y por eso termina con la supresión de la situación de privación de libertad ${ }^{4}$.

Es importante explicitar que esta concepción de la estructura del delito permanente implica un rechazo de la concepción tradicional, que efectivamente entiende que el concepto de delito permanente está vinculado a una especial modalidad de consumación:

Así, se afirma que en los delitos permanentes no hay un momento consumativo sino más bien un período o estado de consumación, es decir, la consumación se inicia con la creación del estado antijurídico y acaba con la supresión de este estado $^{5}$.

En la doctrina chilena, esta concepción es mayoritaria ${ }^{6}$. El problema, sin embargo, radica en su incompatibilidad con la noción misma de consumación, pues "[p]or consumación se entiende en la doctrina el momento en que se realizan todos los elementos del tipo"7. Por lo demás, sólo si la consumación corresponde a un instante, tiene sentido la contraposición binaria entre tentativa y delito consumado. El instante en que el hecho pasa de constituir una realización parcial del tipo de delito (lo cual tiene lugar a partir del principio de ejecución, que también corresponde a un instante, por más difícil que sea su determinación) a constituir una realización completa del tipo de delito, es el instante en que el delito pasa de tentado a consumado.

La consumación de los delitos permanentes, y por ende la consumación del secuestro, como toda consumación, ocurre instantáneamente. Por eso, lo que diferencia a los delitos permanentes de otras clases de delitos no es que en ellos la consumación corresponda a un lapso más o menos prolongado. Tampoco se distinguen los delitos permanentes con suficiente precisión cuando se afirma, en palabras de la Corte, que tras su consumación "se origina un estado o situación susceptibles de ser prolongados en el tiempo, que constituyen subsistencia de esa conducta" (considerando 36). Pues hay muchos delitos que suponen que con su consumación ha de constituirse un estado de cosas susceptible de prolongarse (indefinidamente) en el tiempo. Esto es el caso en los

\footnotetext{
3 Jakobs, Derecho Penal Parte General, Marcial Pons, Madrid, 1997, Apartado 25, núm. 1g.

${ }^{4}$ Kindhäuser (U.), Lebrbuch des Strafrechts Besonderer Teil I, Nomos, Baden-Baden, 2003, \ 15, núm. 17.

${ }^{5}$ Muñoz Sánchez, El delito de detención, Trotta, Madrid, 1992, p. 141.

${ }^{6}$ Cury (E.), Derecho Penal Parte General, Ed. Jurídica de Chile, Santiago, 1992, Tomo II, p. 264; Etcheberry (A.), Derecho Penal, Ed. Jurídica de Chile, Santiago, 1997, Tomo I, p. 226; Politoff, Matus, Ramírez, Lecciones de Derecho Penal Chileno Parte General, Ed. Jurídica de Chile, Santiago, 2003, pp. 190-191.

7 Muñoz Sánchez, op. cit., p. 142.
} 
delitos de estado. Por ejemplo, quien sustrae una cosa ajena sin la voluntad de su dueño da lugar a que, tras la consumación del hurto (= constitución de nueva custodia sobre la cosa), se origine un estado de cosas que puede prolongarse indefinidamente en el tiempo. Pero esto no significa que el hurto constituya un delito permanente. El hurto es un delito de estado y no un delito permanente.

La Corte acierta al agregar que ese estado de cosas que se prolonga en el tiempo, en el ámbito de los delitos permanentes, se corresponde con la subsistencia de la conducta típica. Aquí sí aparece la particularidad de los delitos permanentes: en ellos, lo permanente no es la consumación, sino la ejecución del comportamiento delictivo. Después de que alguien sustrae una cosa ajena sin la voluntad de su dueño, se origina un estado de cosas contrario a derecho, pero eso no significa que la ejecución del hurto se mantenga indefinidamente en el tiempo. En el secuestro, sin embargo, tras la consumación, que corresponde a un instante, el hecho delictivo puede continuar ejecutándose sin que, empero, se afirme más de una realización delictiva.

Por esto es que el secuestro se corresponde con un caso de unidad jurídica de acción: pese a que la comisión de un secuestro puede suponer la realización de varias acciones en sentido natural, el tipo de delito conduce a la consideración de ese conjunto de acciones como una sola acción (en sentido jurídico), y por ende, como un solo delito. Así, el secuestro, en tanto delito permanente, constituye un tipo que enlaza acciones: la ejecución de los delitos permanentes "puede extenderse temporalmente del modo en que se extiende la producción del resultado [en el secuestro: la situación de privación de libertad], sin que se pierda la unidad de la infracción"s. Que el secuestro sea un delito permanente significa que la intensificación cuantitativa de la lesión del bien jurídico no da lugar a la afirmación de más de una infracción punible.

Lo distintivo del secuestro, en tanto delito permanente, es que su consumación (instantánea) puede no sólo no coincidir, sino que diferir significativamente de la terminación del delito, esto es, el momento del cese de la ejecución del hecho que corresponde a la descripción legal del comportamiento punible. Esto significa que puede haber un espacio considerable de tiempo entre la consumación del secuestro y la actualización de las consecuencias normativas que se producen con su terminación. En lo que aquí interesa, puede destacarse que tanto la determinación de la ley penal aplicable como la determinación del momento en que empieza a correr el plazo de prescripción de la acción penal forman parte de esas consecuencias.

Las razones por las cuales la consumación del delito no implica la actualización de dichas consecuencias, que se suspenden hasta su terminación, son bastante obvias desde un punto de vista de política criminal. El autor de un delito (permanente) que aún no termina es el autor de un delito que sigue ejecutándose. Si una ley entra en vigencia después del principio de ejecución del hecho y antes de su terminación, la aplicación de esa ley al hecho no es retroactiva. La aplicación de esta ley al sujeto no infringe en modo alguno la expectativa de certeza e imparcialidad que se sintetiza en el principio de legalidad penal, como sí lo haría la aplicación de una ley que entra en vigencia cuando el hecho ya no sigue ejecutándose. Tampoco se quebranta expectativa de confianza alguna si mientras tiene lugar la ejecución del hecho se altera el plazo de prescripción de la acción penal, como sí ocurre si esto ocurre tras el cese de la ejecución del delito.

${ }^{8}$ Jakobs (G.), op. cit., Apartado 32, núm. 27. 
REJ - Revista de Estudios de la Justicia - No 5 - Año 2004

En este punto se constata lo problemático del fallo de la Corte Suprema, como se observa en el siguiente pasaje de la sentencia:

Que en el caso en estudio, en el evento que los sentenciados expresaren en que lugar se encuentra la víctima, recién ahí comenzaría a contarse la prescripción a su favor, y si esta estuviera muerta, habría que determinar la data del fallecimiento para, en primer término, ver si se encontraba comprendida en el periodo amparado por la amnistía, y en caso de no estarlo, comenzar el cómputo de la prescripción (considerando 38).

Es manifiesta la superposición de consideraciones sustantivas y consideraciones procesales en el razonamiento de la Corte. Esta parece imponer una carga probatoria a los imputados por secuestro, en términos tales que la única forma de librarse de la imputación por la perduración de la ejecución del secuestro consiste en probar que la víctima del secuestro ya no lo es: o bien por haber sido puesta en libertad, o bien por haber pasado de víctima a víctima de homicidio (que no es un delito permanente). La imputación por secuestro, de este modo, se convierte en la imputación por un delito de sospecha, lo cual desconoce que en el marco del proceso penal, la prueba de la ejecución del hecho punible corresponde a quien lleva adelante la persecución penal, lo cual es independiente de que el hecho punible en cuestión constituya o no un delito permanente. Este es el déficit de la idea de delito permanente como delito cuya consumación es permanente: parece que bastaría probar que hubo consumación del delito para que pueda asumirse que esa consumación ha "permanecido" en el tiempo. Cuando se advierte, en cambio, que lo permanente no puede ser la consumación (que es un instante) sino la ejecución del delito, resulta claro que la acreditación de que el delito se consumó no puede sin más implicar la asunción de que sigue ejecutándose hasta el presente.

Lo anterior tiene consecuencias para la determinación judicial del momento de la terminación del delito de secuestro. El delito de secuestro ha de considerarse terminado, para los efectos del proceso penal, en el último momento respecto del cual haya prueba suficiente de la continuación de la ejecución del hecho punible. Esto no implica que pueda descartarse que tras ese momento el hecho punible no siguió cometiéndose. Lo que es el caso (un hecho) no tiene porqué coincidir con lo que es el caso. A menos que se siga alguna variante de constructivismo radical, debe asumirse esta diferencia. Pero asumir la brecha no implica asumir que el costo de la superación de la incertidumbre deba ser soportado por el imputado en el proceso penal. Esto es lo que el principio in dubio pro reo proscribe.

La justificación correcta de la decisión que la Corte valida con su sentencia no puede encontrarse en una alteración de las estructuras ni del secuestro como delito permanente ni de las reglas probatorias del proceso penal. La vía correcta sólo puede ser aquélla cuya plausibilidad la Corte tangencialmente sugiere: la no-aplicación del DL de amnistía. Pero no porque se trate de hechos supuestamente ejecutados hasta el presente, sino porque la validez o la aplicabilidad de ley de amnistía pueden ser jurídicamente controvertida. 
Mañalich - El secuestro como delito permanente ante el DL de amnistía

\section{El secuestro frente a la regulación internacional de la desaparición forzada de personas}

En el análisis de las consecuencias que la Corte atribuye a la consideración del secuestro como delito permanente, no debe descuidarse la referencia a la Convención Interamericana sobre Desaparición Forzada de Personas, de 9 de junio de 1994, así como al Estatuto de Roma9. En su sentencia de casación, la Corte sostuvo que el sentido de la referencia en el fallo de segunda instancia había consistido en "ilustrar la decisión", de modo de "reforzar aún más la idea del respeto a la vida y dignidad de las personas y de quienes tienen el justo y legítimo derecho de conocer el paradero de los que han sido detenidos" (considerando 18).

A este respecto, es fundamental tener en consideración el artículo II de la Convención Interamericana sobre Desaparición Forzada de Personas:

Para los efectos de la presente Convención, se considera desaparición forzada la privación de la libertad a una o más personas, cualquiera que fuere su forma, cometida por agentes del Estado o por personas o grupos de personas que actúen con la autorización, el apoyo o la aquiescencia del Estado, seguida de la falta de información o de la negativa a reconocer dicha privación de libertad o de informar sobre el paradero de la persona, con lo cual se impide el ejercicio de los recursos legales y de las garantías procesales pertinentes.

A continuación, el artículo III especifica el contenido de la obligación que contraen los Estados partes que ratifican la convención:

Los Estados Partes se comprometen a adoptar, con arreglo a sus procedimientos constitucionales, las medidas legislativas que fueren necesarias para tipificar como delito la desaparición forzada de personas, y a imponerle una pena apropiada que tenga en cuenta su extrema gravedad. Dicho delito será considerado como continuado o permanente mientras no se establezca el destino o paradero de la víctima.

El artículo 7.1 del Estatuto de Roma, por su parte, incluye la desaparición forzada de personas dentro del catálogo de los "crímenes de lesa humanidad", delito que es definido en el artículo 7.2. letra i), en los términos siguientes:

Por «desaparición forzada de personas» se entenderá la aprehensión, la detención o el secuestro de personas por un Estado o una organización política, o con su autorización, apoyo o aquiescencia, seguido de la negativa a informar sobre la privación de libertad o dar información sobre la suerte o el paradero de esas personas, con la intención de dejarlas fuera del amparo de la ley por un período prolongado.

Es claro que el delito tipificado en la Convención Interamericana sobre Desaparición Forzada de Personas, así como el delito tipificado en el Estatuto de Roma,

\footnotetext{
${ }^{9}$ En el considerando 18 de la sentencia de la Corte Suprema, se hace asimismo referencia a la doctrina de la Comisión de Derecho Internacional de la ONU y a la resolución que creó el tribunal ad-hoc para la Ex Yugoslavia.
} 
no resultan aplicables como títulos de incriminación al caso sobre el cual recayó el pronunciamiento de la Corte Suprema chilena. La propia Corte parece sugerir que la razón de esto se encontraría en que se trataría de "legislación no vigente en nuestra Patria al momento de ocurrir los hechos" (ibid). Pero esto no es correcto. Aun cuando los hechos hubiesen acaecido después de la ratificación del respectivo tratado por el Estado de Chile, e incluso suponiendo que en tal caso el tratado formaría parte del derecho chileno vigente (con arreglo a la norma del artículo $5^{\circ}$ inciso $2^{\circ}$ de la Constitución de 1980), el delito de desaparición forzada de persona, tal como está tipificado en dichos tratados, no sería título de incriminación directamente aplicable a los hechos en cuestión.

En virtud de la ratificación de la convención interamericana, el Estado de Chile se ha comprometido a tipificar la desaparición forzada de personas como delito autónomo en su derecho interno, lo cual no equivale, empero, a que la sola ratificación del tratado implique tal tipificación. De ser así, no tendría sentido aseverar que el Estado de Chile se ha obligado a ello. El legislador chileno no ha tipificado el delito de desaparición forzada de personas en el derecho interno.

Hay buenas razones para criticar los términos en los que el Estado de Chile ha quedado obligado a sancionar penalmente la desaparición forzada de personas ${ }^{10}$. El Estado de Chile no sólo ha contraído un deber de punición, sino más precisamente un deber de tipificación. Desde el punto de vista de la intensidad de las exigencias que el mandato supra-legal de punición impone al legislador, Bascuñán Rodríguez sugiere distinguir entre deberes de incriminación, deberes moderados de tipificación y deberes extremos de tipificación ${ }^{11}$. Esta distinción presupone entender el establecimiento de normas como un acto de habla ${ }^{12}$. Un deber de incriminación se concreta en un deber que sólo impone exigencias en el nivel proposicional y en el nivel ilocucionario del acto habla, pero no en el nivel del acto de emisión. Así, lo que exige un deber de incriminación es "que cierto comportamiento [referencia como acto proposicional] se encuentre descrito como supuesto de hecho de un enunciado que impute [ilocución] una sanción penal como consecuencia de ese comportamiento", de modo que "[l]a elección de la fórmula lingüística [acto de emisión] es prerrogativa del legislador"13. Un deber moderado de tipificación es un deber que se concreta en una exigencia que se plantea en el nivel del acto de emisión: "que el derecho legal contemple un tipo penal, identificable como delito sui generis o autónomo dentro del catálogo de conductas punibles"14. Finalmente, un deber extremo de tipificación se traduce en un deber de congruencia máxima en el nivel del acto de emisión, o sea, "un deber de transcribir los términos y expresiones del texto autoritativo supralegal en el texto autoritativo legal"15.

Puede discutirse la cuestión de si en virtud de la ratificación de la Convención Interamericana sobre Desaparición Forzada de Personas el Estado de Chile ha contraído un deber moderado o un deber extremo de tipificación. En todo caso, parece claro que el

\footnotetext{
10 Vid. Medina (G.), La desaparición forzada de personas como forma calificada de detención ilegal cometida por funcionario público, Memoria de prueba, Universidad de Chile, Santiago, 2001.

11 Bascuñán Rodríguez (A.), "Derechos fundamentales y derecho penal", en, VV.AA., Los derechos fundamentales, Sela 2001, Editores del Puerto, Buenos Aires, 2003, pp. 319 y ss.

12 Vid. infra, nota 24.

13 Bascuñán Rodríguez (A.), op. cit., pp. 330-331.

14 Ibid 331.

15 Ibid.
} 
Estado de Chile no ha contraído un mero deber de incriminación. Si se tratase de un deber de incriminación, la tipificación del secuestro podría bastar para el cumplimiento de ese deber. Esto puede significar que el Estado de Chile aún no cumpla con su obligación internacional. El legislador chileno no ha tipificado la desaparición forzada de personas como un delito autónomo y diferenciado. Pero en todo caso ello no puede conducir a que los tribunales chilenos interpreten y apliquen el delito de secuestro en el sentido de la desaparición forzada de personas. Pues es el legislador, no un tribunal, quien ha de satisfacer el compromiso contraído por el Estado de Chile.

Lo anterior es importante si se advierte cómo la concepción del secuestro como delito permanente que desarrolla la Corte es congruente con la definición de la desaparición forzada de personas, delito que, conforme al artículo III de la convención, "será considerado como continuado o permanente mientras no se establezca el destino o paradero de la víctima".

La equiparación de las nociones de delito continuado y delito permanente que se encuentra en el artículo III de la convención desafía su entendimiento tradicional, al menos desde el punto de vista de la dogmática penal continental. La noción de delito permanente ya se ha examinado. La noción de delito continuado, por su parte, hace referencia a una construcción dogmática, altamente controvertida, que resultaría aplicable a determinados casos de reiteración más o menos inmediata de acciones típicas que presentan una importante relación de semejanza y conexión entre sí, de manera tal de afirmar unidad de acción entre ambas y así negar una realización delictiva múltiple o, al menos, el concurso real ${ }^{16}$. En este sentido, hay una relación de proximidad entre la noción de delito permanente y la noción de delito continuado. En ambos casos, se trata de la fundamentación de una unidad de acción a pesar de la concurrencia de varias acciones en sentido natural. Pero en ningún caso esta relación de proximidad es coincidente con el sentido en que la convención utiliza ambas nociones.

En la convención, la calidad de delito permanente o continuado de la desaparición forzada implica que el delito se entiende seguir cometiéndose hasta que no se determine el paradero de la víctima. Esto se explica en atención al segundo elemento con que el artículo II complementa la definición del delito: la falta de información o la negativa a reconocer la privación de libertad o la negativa a informar sobre el paradero de la víctima. De este modo, la desaparición forzada de personas se encuentra tipificada como un delito en que concurren dos núcleos de actividad delictiva, a saber, la comisión de una privación de libertad, y la omisión de alguna de las siguientes tres conductas alternativas: informar sobre el hecho de la privación de libertad, reconocer la privación de libertad o informar sobre el paradero de la víctima. Así, el delito de desaparición forzada se compone tanto de la comisión de privación de libertad como de una omisión (propia) a la cual debe poder imputarse un resultado distinto del resultado que es constitutivo del injusto de la privación de libertad: "el impedimento del ejercicio de los recursos legales y de las garantías procesales pertinentes"17. Es la imputación de una omisión semejante lo que subyace a la

\footnotetext{
${ }^{16}$ Negar el concurso real no equivale a negar la pluralidad de realizaciones típicas. Pues un concurso ideal también implica pluralidad de realizaciones típicas; su diferencia con el concurso real se encuentra en que el concurso ideal supone unidad de acción. El delito continuado supone unidad de acción, y según algunos autores puede conducir a la aplicación del régimen del concurso ideal.

${ }^{17}$ En la tipificación de la desaparición forzada de personas en el Estatuto de Roma, se debilita la exigencia de que a la omisión de informar pueda imputarse un menoscabo de la protección legal de los sujetos privados de
} 
sentencia de la Corte Suprema, pues en sus propios términos, sólo cuando los imputados proporcionen información acerca del paradero de la víctima podrá entenderse terminado el delito de secuestro.

La desaparición forzada de personas está tipificada como un delito de sospecha. El autor de la privación de libertad debe no sólo soportar la imputación de este injusto, sino también la presunción de la comisión de un homicidio. De este modo se infringe abiertamente el principio de culpabilidad, al menos en dos de sus concreciones inequívocamente reconocidas: la presunción de inocencia y la prohibición de (forzar a) declarar contra sí mismo. Si el Estado chileno cumple con su deber supra-legal de tipificación, podrá reprochársele esta erosión de una garantía fundamental del Estado de Derecho. Pero a la Corte Suprema no sólo debe reprocharse esto, sino también el desconocimiento de las exigencias del principio de legalidad para la interpretación de la ley penal. Pues el delito base de secuestro del artículo 141 del Código Penal, correctamente interpretada esta disposición, se agota en el injusto de la privación de libertad.

\section{La prueba del homicidio en el proceso penal}

En su justificación de su aseveración de que el secuestro imputado en el proceso debe entenderse ejecutado hasta el presente, la Corte Suprema sostuvo que el hecho

sólo puede enmarcarse en la figura del artículo 141 del Código Penal [...] sin que obre ningún antecedente que permita insertar tales sucesos en alguna otra figura penal, especialmente la del secuestro con resultado de muerte, por cuanto no consta en autos su defunción como aconteció con otras personas detenidas en similares circunstancias y que sus cuerpos fueron hallados; ello no ocurre en el caso sub lite y es fundamento de todo juicio penal la acreditación de la existencia del hecho punible y su comprobación por los medios que admite la ley, el primer objeto del mismo; por lo que no es posible concluir la muerte del ofendido (considerando 31).

Desde ya, es incorrecto que lo que decida la posibilidad de encuadrar el hecho en un tipo de delito sea que el mismo no pueda ser encuadrado en otro. Esto es propiamente falaz. Ciertamente, es posible que una condición para que un hecho pueda subsumirse en un tipo de delito puede consistir en que el mismo hecho no pueda subsumirse en otro tipo. Así por ejemplo, para que un hecho satisfaga el tipo de la estafa se requiere que ese hecho no satisfaga el tipo del hurto. Pero es claro que en tal caso se trata de una condición necesaria y no de una condición suficiente. Por eso, en el caso analizado, que el hecho no pueda (supuestamente) encuadrarse en la hipótesis de secuestro con resultado de muerte (o en el tipo base del homicidio), no implica que sí deba ser encuadrado en el tipo base del secuestro; esto sólo será el caso si efectivamente se ha realizado este tipo de delito, lo cual no depende, al menos no totalmente, de que no se haya realizado otro tipo de delito.

libertad, pues conforme a la letra i) del artículo 7.2 basta que a la omisión pueda imputarse "la intención de dejarlas fuera del amparo de la ley por un periodo prolongado". Así, mientras la convención interamericana configura la omisión de informar posterior a la privación de libertad como una omisión propia de resultado, el Estatuto de Roma la configura como una omisión propia de resultado cortado, pues la intención requerida no constituye sino una tendencia interna trascendente. 
Mañalich - El secuestro como delito permanente ante el DL de amnistía

Más allá de esto, sin embargo, lo que tiene que destacarse es una posible interpretación del considerando de la Corte en relación con las exigencias procesales para la acreditación del resultado de muerte que a ella parece subyacer. En la medida en que se interprete la consideración de la Corte en el sentido de que en el proceso penal en cuestión no se encuentra legalmente probado el acaecimiento del resultado de muerte del sujeto privado de libertad, entonces no hay problema alguno. Obviamente, un resultado sólo puede imputarse a una acción, en el marco del proceso penal, en la medida en que ese resultado haya sido acreditado de conformidad con las exigencias legales. El problema puede surgir si la consideración de la Corte se interpreta en el sentido de que el resultado de muerte no puede ser acreditado si el cuerpo de la víctima no es hallado. La base para esta interpretación se encuentra en la referencia al hecho de que en otras causas sí se ha hallado los cuerpos, así como en la alusión a "la acreditación de la existencia del hecho punible y su comprobación por los medios que admite la ley" como objeto fundamental del proceso penal. Esto, porque entre las reglas que determinan el como por el cual debe acreditarse el hecho punible, el Código de Procedimiento Penal establece algunas reglas especiales para el homicidio, que parecerían dar a entender que el hallazgo del cadáver es condición necesaria para la comprobación del delito.

En efecto, el $\int 2$ del Título III del Libro II del Código de Procedimiento Penal regula "la comprobación del delito en casos especiales". El primer apartado se refiere a casos de homicidio, aborto y suicidio. El inciso $1^{\circ}$ del artículo 121 establece lo siguiente:

Cuando se sospeche que la muerte de una persona es el resultado de un delito, se procederá, antes de la inhumación del cadáver o inmediatamente después de exhumado, a efectuar la descripción ordenada por el artículo 112, a practicar el reconocimiento y autopsia del cadáver y a identificar la persona del difunto.

Es importante precisar en qué consiste el "caso especial" a que se refiere la regla expresada en esta disposición. La segunda interpretación del considerando tendría que entender que el caso especial correspondería a todo homicidio: si no se halla el cuerpo de la víctima, entonces no puede ser probado homicidio alguno. Esta interpretación de la disposición legal sería incorrecta. Pues el caso especial es aquel en que se encuentra el cadáver de una persona y hay sospechas de que la muerte puede corresponder al resultado de un delito de homicidio, que no corresponde (necesariamente) a todo caso de homicidio. Esto puede argumentarse tomando en consideración la regla del artículo 135 del mismo código:

\section{Si se encontrare ahorcado a un individuo, la investigación se dirigirá principalmente} a establecer:

1. ${ }^{\circ}$ Si el sujeto fue ahorcado vivo o suspendido después de muerto; y

2. ${ }^{\circ}$ Si se ahorcó a sí mismo o fue ahorcado por otro.

El caso del artículo 135 es un caso especial frente al caso especial del artículo 121. En ambos casos, lo especial no es el delito (presuntamente) cometido, sino la circunstancia del hallazgo de un cadáver. Esto es suficientemente claro en la regla del artículo 135, en que el delito en cuestión puede no corresponder a un homicidio, sino a un auxilio al suicidio (artículo 393 CP).

Para reforzar el argumento, hay que considerar el modo en que la regla del artículo 121 del Código de Procedimiento Penal ha sido trasladada al Código Procesal 
Penal. El artículo 201 del nuevo código, que se titula "hallazgo de un cadáver", dispone, en su inciso $1^{\circ}$, que

Cuando hubiere motivo para sospechar que la muerte de una persona fuere el resultado de un hecho punible, el fiscal procederá, antes de la inhumación del cadáver o inmediatamente después de su exhumación, a practicar el reconocimiento e identificación del difunto y a ordenar la autopsia.

Es claro que en lo fundamental se trata de la misma regla. Lo importante de la disposición del Código Procesal Penal frente a la del Código de Procedimiento Penal es que ya en el encabezado de la disposición queda de manifiesto que el ámbito de aplicación de la regla no se extiende todo caso en que el hecho investigado (presumiblemente) corresponde a un delito de homicidio, sino que se restringe a aquellos casos en que por alguna razón aparece un cadáver, pudiendo sospecharse que ha tenido lugar un homicidio.

Es obvio que en determinados casos la falta del hallazgo del cadáver puede importar la imposibilidad de acreditar el resultado del homicidio. Esto ocurrirá siempre que no haya otro elemento de prueba que posibilite tal acreditación. Pero esto no puede equivaler a afirmar que sin cadáver no puede acreditarse un homicidio, o cualquier otro tipo de delito o hipótesis calificada que requiera la producción de un resultado de muerte. Esa imposibilidad de acreditar el resultado de homicidio sólo puede ser contingente, y no necesaria. Pues es posible que haya casos en que, ya sea por la misma conducta constitutiva del homicidio o por una conducta posterior, desaparezca el cadáver o sea imposible su hallazgo. El sujeto que quema a otro hasta su incineración comete un homicidio. Y este homicidio no puede per se estar más allá de la competencia epistémica del sistema penal.

Hasta el momento la sentencia de la Corte Suprema ha sido examinada en términos de contexto de justificación. Si la decisión se examina en términos de contexto de descubrimiento, probablemente haya que decir que la Corte ha atribuido las consecuencias ya criticadas a la consideración del secuestro como delito permanente y ha enfatizado la imposibilidad de tener por acreditado un delito de homicidio (lo cual no implica necesariamente la posible interpretación más arriba rechazada), porque de lo contrario, bajo la representación de la Corte, la inaplicación del DL de amnistía se volvería aun más problemática. Ocurre, sin embargo, que la propia Corte ha ofrecido razones, aunque sólo en el nivel de obiter dictum, para justificar la inaplicación del DL de amnistía. Esto se analizará en lo que sigue, pero después de comentar críticamente la tesis acerca de la oportunidad procesal en que debe declararse la amnistía por el tribunal que subyace a la sentencia.

\section{Reconocimiento de la amnistía en el proceso penal}

En relación con este punto, la Corte sostuvo que

no es posible, al parecer de esta Corte, aplicar dicha institución [la amnistía] cuando no se han fijado los presupuestos mínimos ello [sic] al no haberse determinado la fecha en la cual concluyó el injusto en estudio. De esta manera, no parece razonable que se invoque la aplicación de la amnisis u olvido cuando en la práctica el delito no ha finalizado en su perpetración (considerando 30). 
El argumento de la Corte puede descomponerse en dos partes. La primera cuestión se refiere a la exigencia de que se establezcan los presupuestos mínimos para la aplicación judicial de la amnistía. Lo que aquí se escucha es un eco de la denominada "doctrina Aylwin", según la cual la aplicabilidad de la amnistía se tendría que sujetar a la determinación precisa del hecho punible y del sujeto culpable al cual se extendería esta causa de extinción de la responsabilidad penal. En los términos del Código de Procedimiento Penal, esta tesis implica que la aplicación de la amnistía requeriría el agotamiento de la investigación en la etapa del sumario, pues sólo después procede la dictación del sobreseimiento definitivo, una de cuyas causales es, efectivamente, la extinción de responsabilidad por amnistía (artículo 408 No 5 CPP en relación con artículo $\left.93 \mathrm{~N}^{\circ} 3 \mathrm{CP}\right)$.

El problema de la doctrina Aylwin es que ella resulta conflictiva frente a otra regla del Código de Procedimiento Penal, a saber, la expresada en el artículo 107, que establece:

Antes de proseguir la acción penal, cualquiera que sea la forma en que se hubiere iniciado el juicio, el juez examinará si los antecedentes o datos suministrados permiten establecer que se encuentra extinguida la responsabilidad del inculpado. En este caso pronunciará previamente sobre este punto un auto motivado, para negarse a dar curso al juicio.

La defensa de la doctrina Aylwin supone afirmar una antinomia entre la regla del artículo 107 y la del artículo $408 \mathrm{~N}^{\circ}$ 5, y postular su solución a favor de la segunda. Pero esta tesis es falaz. No es claro que sea correcto afirmar una antinomia entre ambas reglas. Sería razonable afirmar que a cada una corresponde un ámbito material de validez distinto: el artículo 107 se aplica a casos en que ya al iniciarse el sumario es claro para el juez que respecto de inculpado concurre una causa de extinción de responsabilidad penal, por ejemplo, una amnistía; el artículo $408 \mathrm{~N}^{\circ} 5$ se aplica a casos en que ello puede determinarse sólo después de agotada la investigación (por ende, al final del sumario). Si hubiese una antinomia entre ambas reglas, en todo caso se trataría de una situación de conflicto parcial, referido a los casos en que al inicio del proceso penal hay bases suficientes para considerar extinguida la responsabilidad penal. Esta antinomia, sin embargo, tendría que ser resuelta a favor de la regla del artículo 107.

Una tesis que favorece el desarrollo de un proceso penal que necesariamente ha de conducir al sobreseimiento definitivo no es una tesis aceptable en atención a los criterios de justicia política que condicionan la legitimidad del proceso penal. Uno de estos criterios está constituido por el principio de proporcionalidad, y en particular por la prohibición de exceso que de él se deriva. El desarrollo del proceso penal supone que la contingencia básica que lo justifica se mantenga en tanto contingencia: la contingencia de que, bajo el procedimiento jurídicamente reglado, el imputado haya de ser condenado o absuelto. Esta es una condición de imparcialidad de la intervención punitiva estatal. Si $a b$ initio es manifiesto (bajo condiciones institucionales vinculantes) que el proceso penal en cuestión debe conducir a la absolución, el Estado no puede estar legitimado para llevar adelante el complejo de intervenciones y medidas, necesariamente lesivas para esferas de autonomía jurídicamente reconocidas, que supone el proceso penal. En este sentido, es notable que la perseguibilidad del hecho concreto, y específicamente la no-inhibición de la persecución punitiva vía amnistía, sea considerada un auténtico presupuesto del proceso 
penal, esto es, una circunstancia de la que "depende la admisibilidad de todo el procedimiento"18.

Ciertamente, puede haber casos en que al inicio del proceso penal no sea posible determinar con seguridad la aplicabilidad de la amnistía al hecho investigado: por ejemplo, por no haber indicios suficientes para determinar el periodo de tiempo en que se cometió el delito, en circunstancias de que la amnistía en cuestión se extienda a hechos delimitados en cierto espacio de tiempo. Esta parecería ser la situación que se da en el caso en que recayó el pronunciamiento de la Corte Suprema. No obstante, la razón para controvertir la inexorabilidad del sobreseimiento definitivo por aplicación del DL de amnistía se encuentra en una tesis que tergiversa el sentido de la condición de delito permanente del secuestro.

\section{Inaplicabilidad del DL de amnistía. Dos significados de "impunidad"}

Conforme a lo aseverado más arriba, fue a título de obiter dictum que la Corte Suprema sugirió una vía que parece más prometedora para justificar la inaplicación del DL 2191 de 1978: la afirmación de una infracción de normas establecidas por tratados internacionales de DD.HH. ratificados por Chile. Aunque no parece claro en el texto de la sentencia de casación, se trata de un obiter dictum, puesto que esta línea de argumentación no es necesaria para la consecución de la decisión establecida en la sentencia: la afirmación de que el secuestro en cuestión debe considerarse cometido hasta el presente implica que el hecho no queda cubierto por la amnistía, que se extiende a hechos acaecidos hasta el 10 de marzo de 1978. Por esto, es incorrecta la aseveración de que la Corte resolvió no aplicar la amnistía a este caso. La decisión de la Corte parece suponer que la parte del hecho constitutivo de secuestro que sí corresponde al periodo de tiempo cubierto por la amnistía no es punible. Este es todo el sentido de la concepción de la estructura del secuestro como delito permanente que acogió la Corte. El punto está en que la Corte no advierte que su obiter dictum está en conflicto con el fundamento nuclear de su decisión, pues esta línea argumental sí puede conducir a la (auténtica) inaplicación del DL de amnistía.

En el considerando 34 de la sentencia, la Corte hizo referencia a normas de rango supra-legal de derecho internacional humanitario, en particular, al IV Convenio de Ginebra, relativo a la protección debida a las personas civiles en tiempo de guerra, ratificado por Chile con anterioridad al (principio de ejecución del) hecho. El artículo $3^{\circ}$ de este convenio establece lo siguiente:

En caso de conflicto armado que no sea de índole internacional y que surja en el territorio de una de las Altas Partes Contratantes, cada una de las Partes en conflicto tendrá la obligación de aplicar, como mínimo, las siguientes disposiciones:

1) Las personas que no participen directamente en las hostilidades, incluidos los miembros de las fuerzas armadas que hayan depuesto las armas y las personas puestas fuera de combate por enfermedad, herida, detención o por cualquier otra causa, serán, en todas las circunstancias, tratadas con humanidad, sin distinción alguna de índole desfavorable, basada en la raza, el color, la religión o la creencia, el sexo, el nacimiento o la fortuna, o cualquier otro criterio análogo.

${ }_{18}$ Roxin (C.), Derecho Procesal Penal, Editores del Puerto, Buenos Aires, 2000, pp. 165-167. 
Mañalich - El secuestro como delito permanente ante el DL de amnistía

A este respecto, se prohíben, en cualquier tiempo y lugar, por lo que atañe a las personas arriba mencionadas:

a) los atentados contra la vida y la integridad corporal, especialmente el homicidio en todas sus formas, las mutilaciones, los tratos crueles, la tortura y los suplicios;

b) la toma de rehenes;

c) los atentados contra la dignidad personal, especialmente los tratos humillantes y degradantes;

d) las condenas dictadas y las ejecuciones sin previo juicio ante un tribunal legítimamente constituido, con garantías judiciales reconocidas como indispensables por los pueblos civilizados.

El artículo 146, también mencionado por la Corte, por su parte establece que:

Las Altas Partes Contratantes se comprometen a tomar todas las oportunas medidas legislativas para determinar las adecuadas sanciones penales que se han de aplicar a las personas que hayan cometido, o dado orden de cometer, una cualquiera de las infracciones graves contra el presente Convenio definidas en el artículo siguiente.

Cada una de las Partes Contratantes tendrá la obligación de buscar a las personas acusadas de haber cometido, u ordenado cometer, una cualquiera de las infracciones graves, y deberá hacerlas comparecer ante los propios tribunales, sea cual fuere su nacionalidad. Podrá también, si lo prefiere, y según las condiciones previstas en la propia legislación, entregarlas para que sean juzgadas por otra Parte Contratante interesada, si ésta ha formulado contra ella cargos suficientes.

La conclusión que la Corte alcanza es que:

en consecuencia, el Estado de Chile se impuso, al suscribir y ratificar los citados Convenios, la obligación de garantizar la seguridad de las personas que pudieren tener participación en conflictos armados dentro de su territorio, especialmente si fueren detenidas, quedando vedadas las medidas tendientes a amparar los agravios cometidos contra personas determinadas o lograr la impunidad de sus autores, teniendo especialmente presente que los acuerdos internacionales deben cumplirse de buena fe (considerando 35).

La inferencia que hace la Corte es problemática, fundamentalmente en lo relativo a la obligación de evitar la impunidad de los responsables. Que esta obligación conlleve una prohibición de dictar amnistía respecto de los hechos que constituyen infracciones al convenio depende, en buena medida, de qué se entienda por "amnistía" y, sobretodo, por "impunidad".

Desde ya, puede ser importante tener en cuenta que el propio Protocolo Adicional II a los Convenios de Ginebra, de 1979, que fuera ratificado por el Estado de Chile en 1991, establece en su artículo 6.5 que

A la cesación de las hostilidades, las autoridades en el poder procurarán conceder la amnistía más amplia posible a las personas que hayan tomado parte en el conflicto armado o que se encuentren privadas de libertad, internadas o detenidas por motivos relacionados con el conflicto armado. 
Por más que el Protocolo Adicional II haya sido suscrito y ratificado con posterioridad a la ratificación de los convenios, es claro que la norma expresada en la disposición transcrita vuelve difícil aceptar una interpretación de la prohibición de amnistía en términos de una prohibición absoluta. Según Ambos, "[a]l momento de la suscripción del protocolo (1979) no se pensó en modo alguno en posibilitar las amnistías que contravinieran los deberes de penalización consagrados en el derecho internacional"19. La pregunta se dirige, entonces, a la determinación de las amnistías que importan tal contravención de los deberes supra-legales de punición.

Ambos sostiene que las distintos tratados y convenciones "señalan que el derecho internacional no establece una prohibición absoluta de las amnistías" 20 . Parecería que la distinción central puede formularse entre auto-amnistías y hetero-amnistías, siendo admisibles las últimas, no las primeras ${ }^{21}$. La razón por la cual una auto-amnistía resulta inaceptable es que en ella el sentido de la amnistía es la auto-exoneración de quienes, detentando el poder durante y después de los hechos, garantizan de este modo su impunidad. Por eso es que tiene sentido hablar en este contexto de delitos de impunidad, esto es,

delitos contra intereses fundamentales, cometidos por personas a quienes les corresponde mantener la vigencia del orden establecido, en forma sistemática y/o generalizada, y bajo condiciones fácticas de impunidad conocidas y asumidas ex ante por los autores de esos delitos 22 .

Frente a esta clase de delitos, "una decisión legislativa posterior de prescindencia de la pena tiene inevitablemente el sentido de confirmación de la comunicación que portaban los delitos"'23.

En este punto se vuelve imprescindible atender al concepto de impunidad. Pues en un sentido trivial, toda amnistía conlleva impunidad, si impunidad significa nopunibilidad. Esto, porque la amnistía no es sino una causa de extinción de responsabilidad penal, esto es, una condición negativa de la punibilidad. Pero es claro que el concepto de impunidad, al menos en el contexto de los delitos de impunidad, tiene otro sentido. En lo que sigue se ofrecerá una sugerencia para la clarificación de este sentido, sobre la base de un análisis de la relación entre pena y amnistía.

\section{La amnistía como equivalente funcional de la pena. La auto-amnistía como contradicción performativa}

Bajo la autocomprensión normativista del sistema penal contemporáneamente dominante, la función de la pena consiste en restablecer comunicativamente la vigencia de la norma. El delito, por su significado comunicativo, niega la vigencia de la norma; la pena,

\footnotetext{
19 Ambos (K.), Impunidady Derecho Penal Internacional, Diké, Medellín, 1997, p. 281.

20 Ibid 283.

${ }^{21}$ Como la distinción entre autofavorecimiento y favorecimiento externo, ibid 284-287.

22 Bascuñán Rodríguez (A.), op. cit., p. 340.

23 Ibid.
} 
Mañalich - El secuestro como delito permanente ante el DL de amnistía

como acto expresivo, debe confirmar la vigencia de la norma en contra del significado comunicativo del delito. En tanto acto expresivo, la función de la pena puede describirse en términos de la teoría de los actos de habla. Lo que el paradigma actualmente vigente posibilita es entender que la función de la pena se corresponde con su sentido ilocucionario ${ }^{24}$ : el restablecimiento de la norma en la comunicación. La pena se legitima, de este modo, como acción orientada al entendimiento, esto es, como acción comunicativa. Esto es posible, sobretodo, por el condicionamiento de la pena a la imputación de culpabilidad. Así, Kindhäuser:

El reproche de culpabilidad es, más bien, una posibilidad de reaccionar ante el mal del hecho delictivo, no mediante una consideración objetivante del autor, sino bajo el modo de proceder orientado al entendimiento comunicativo ${ }^{25}$.

La persecución de fines mediante la pena importa la instrumentalización de la pena, y así la instrumentalización del culpable. Si la pena no es sino una reacción formalizada, una expresión formalizada de decepción ${ }^{26}$, que importa el re-conocimiento de la vigencia de la norma, entonces la pena ha de considerarse libre de fines (zweckfret). Que la pena produzca intimidación o resocialización es contingente ${ }^{27}$, como por definición son contingentes los efectos perlocucionarios de un acto de habla. Pero la persecución de fines perlocucionarios mediante la pena importa utilizar la pena, y la comunicación, para la interacción estratégica.

La amnistía en todo caso conlleva una renuncia a la pena. La pregunta apunta a cuál es el alcance de esta renuncia. ¿Implica también la amnistía una renuncia al sentido comunicativo generalmente correspondiente a la pena? La respuesta depende de cuál sea la posición de la amnistía en la articulación reflexiva del sistema penal. Si la operación que define al sistema penal es la estabilización contrafáctica de determinadas expectativas, entonces debe evitarse la conclusión de que uno de los mecanismos institucionales por los cuales se auto-reproduce el sistema penal no sea funcional a esa operación.

\footnotetext{
${ }^{24}$ La exposición más estandarizada de la teoría de los actos de habla toma como punto de partida la distinción de Austin entre actos locucionarios, ilocucionarios y perlocucionarios. El acto locucionario corresponde a lo que se dice; el acto ilocucionario, a lo que se hace al decir lo que se dice; y el acto perlocucionario, a las consecuencias de lo que se hace al decir lo que se dice. De ahí que parezca preferible hablar de "efectos perlocucionarios". Sobre esto, Habermas, Teoría de la acción comunicativa I, Taurus, Madrid, 1999, pp. 367-378. Para Habermas, la acción comunicativa corresponde a "aquellas interacciones mediadas lingüísticamente en que todos los participantes persiguen con sus actos de habla fines ilocucionarios y sólo fines ilocucionarios" (ibid). ${ }^{25}$ Kindhäuser (U.), "La fidelidad al derecho como categoría de la culpabilidad", en Revista Peruana de Doctrina y Jurisprudencia Penal, No 1, Lima, 2000, pp. 210-211. Se ha alterado la traducción de algunos términos, para adecuarla mejor al aparato conceptual habermasiano subyacente.

${ }^{26}$ Ibid 212. Fundamental, Strawson, Libertad y Resentimiento, Paidós, Barcelona, 1995.

${ }^{27}$ Jakobs afirma que "[s]ecundariamente, la pena puede impresionar de tal modo al que la sufre o a terceros que éstos se abstengan de realizar hechos futuros. Estos efectos producidos, no por el reconocimiento de la norma, sino por miedo, son algo que cabe desear que se dé por añadidura en la pena, pero no es función de la pena provocar tales efectos" (Jakobs, op. cit., Apartado 1, núm. 16). Que la concepción comunicativa de la pena que corresponde a la moderna teoría de la prevención general positiva implica una validación de una fundamentación retribucionista de la pena, se hace patente en el trabajo posterior de Jakobs, Sobre la teoría de la pena (Universidad Externado de Colombia, Bogotá, 1998) y sobretodo en la monografía de su discípulo Lesch, La función de la pena (Dykinson, Madrid, 1999).
} 
Esta no es sino una manera complicada de decir que la amnistía debe ser considerada un equivalente funcional de la pena. Que la amnistía constituya un equivalente funcional de la pena significa que la amnistía debe hacer posible la solución del conflicto sin pena ${ }^{28}$. Es claro que la amnistía no puede ser entendida como una modalidad de superación cognitiva del conflicto, o sea, como un reconocimiento de que la expectativa generalizada en la norma quebrantada, por la evidencia de su frustración, debe ser abandonada. El sentido que institucionalmente ha de corresponder al DL 2191, por ejemplo, no puede ser que la expectativa de la garantía del ciudadano en contra de actos de terror estatal era infundada. La amnistía tiene que ser entendida como un mecanismo normativo de superación del conflicto: la expectativa defraudada debe ser mantenida, a pesar y en contra de la evidencia de su frustración. ¿Pero cómo y por qué podría ocurrir esto sin pena?

En la respuesta a esta pregunta puede aparecer la especial significación de la amnistía en contextos de justicia transicional. La amnistía, a diferencia de la pena, puede importar el re-conocimiento de la validez de la(s) norma(s) quebrantada(s) sin dejar de mostrar lo peculiar de la situación en que el terror estatal se produce: como dice Atria, una situación en que el autor del delito también puede considerarse víctima ${ }^{29}$. La amnistía puede constituir una expresión institucionalizada de compasión. Si ello es así, la amnistía sólo debería alcanzar a aquellos que efectivamente pueden ser considerados, en algún sentido, víctimas. Según Atria, que sigue a Weil, la condición de esta "victimización" es el padecimiento de la fuerza (de la violencia, que "aplasta a los que toca”), como situación contrapuesta al ejercicio del poder.

Pero para tener este significado pragmático, esto es, para alcanzar el éxito ilocucionario del reconocimiento de la vigencia de la norma, la amnistía debe satisfacer algunas condiciones. A este respecto, es fundamental insistir en que la amnistía importa la extinción de la responsabilidad penal. La amnistía no supone una exclusión de la responsabilidad penal, sino su extinción. Las razones que justifican la amnistía no son razones que desde el punto de vista de la responsabilidad de los sujetos amnistiados operen excluyendo su culpabilidad. La situación en que tiene lugar el terror estatal es peculiar, pero no constituye un estado de necesidad exculpante. La amnistía es una renuncia a la pena que no implica la negación de la responsabilidad. Es más, es posible que el éxito ilocucionario de la amnistía en determinados casos requiera la atribución expresa de responsabilidad.

La amnistía es una renuncia a la pena sin negación de responsabilidad. La responsabilidad penal es el paradigma de responsabilidad que se exige ${ }^{30}$. Como el propio reproche de culpabilidad, la renuncia a la actualización de las consecuencias del reproche, en términos de acción comunicativa, supone la asunción de la perspectiva de segunda persona. Aquí aparece el déficit que padece toda auto-amnistía. La auto-amnistía es la amnistía que se atribuye en primera persona. Esta forma de amnistía jamás puede alcanzar el éxito ilocucionario que podría justificarla: la estabilización normativa de la expectativa defraudada. La auto-amnistía se interpreta como un modo de elusión de las consecuencias de la responsabilidad, y en esa medida, favorece una orientación cognitiva frente a la

\footnotetext{
${ }^{28}$ Vid. Jakobs (G.), Derecho Penal Parte General, Apartado 1, núm. 12-13.

29 Atria (F.), "Terror, reconciliación y responsabilidad" (inédito).

30 Ibid.
} 
Mañalich - El secuestro como delito permanente ante el DL de amnistía

expectativa defraudada. La auto-amnistía es una razón para abandonar la expectativa de intangibilidad del ciudadano frente al poder estatal.

Puesto que la auto-amnistía necesariamente fracasa en el nivel ilocucionario, al no adecuarse a una condición constitutiva del significado institucional de la amnistía, la autoamnistía constituye una (auto)contradicción preformativa: la auto-amnistía niega un presupuesto pragmático del éxito ilocucionario de la amnistía como equivalente funcional de la pena ${ }^{31}$. Lo que la auto-amnistía performa, negando el restablecimiento de la vigencia de la norma, es lo que se llama impunidad.

Por esto una auto-amnistía no puede ser válida, y en este sentido deberían interpretarse los tratados internacionales. Pero debe introducirse una matización. La autoamnistía sólo es tal para aquellos que efectivamente controlan de tal modo el aparato estatal que la renuncia a la pena está a su disposición. Sólo estos incurren, genuinamente, en la contradicción preformativa de liberarse a sí mismos del reproche penal. Para los sujetos involucrados en los hechos, pero ajenos a ese círculo de poder, la amnistía no deja de ser heterónoma. Respecto de éstos, por ende, no existen las mismas razones para la inaplicación del DL de amnistía.

\section{Consecuencias para la prescripción}

La tesis desarrollada precedentemente puede tener consecuencias importantes para la determinación de los efectos jurídicos que tendría la inaplicación del DL de amnistía fundamentada en esos términos. Aquí interesa el problema de la prescripción de la acción penal. Si se declara inaplicable la amnistía, entonces el plazo de prescripción de la acción penal correspondiente a los delitos investigados podría entenderse cumplido. Ciertamente, el problema no se presentará en aquellos casos en que se haya suspendido la prescripción por el ejercicio de la acción penal. El problema surge respecto de aquellos casos en que la auto-amnistía sí inhibió el ejercicio de la acción penal. La solución de este problema exige desentrañar una paradoja: la afirmación de la invalidez de la auto-amnistía requiere reconocerle a lo menos un efecto, a saber, el efecto de la inhibición de la persecución penal.

Para desentrañar esta paradoja hay que volver a la noción de delitos de impunidad. En estos delitos, aquello que define el significado comunicativo del hecho como quebrantamiento de la norma es precisamente la configuración de un estado de cosas en que la persecución punitiva deviene imposible, en este caso, por su inhibición a través de la amnistía. El reconocimiento de la contradicción preformativa en que incurre quien dicta una auto-amnistía exige reconocer su significado pragmático en la constitución de delitos de impunidad. En sentido figurado, para los efectos del cómputo del plazo de prescripción de la acción penal, los delitos de impunidad terminan cuando cesa la situación de impunidad.

Esta solución "figurativa" del problema podría ser objetada bajo el principio de legalidad. Pues es claro que esta dimensión de los delitos de impunidad no encuentra correlato en la descripción legal del hecho punible. Pero debe recordarse que esta

\footnotetext{
${ }^{31}$ Sobre el principio de no-autocontradicción preformativa, Apel, Teoría de la verdad y ética del discurso, Paidós, Barcelona, 1991, pp. 129-137.
} 
dimensión no es la que fundamenta la punibilidad de estos hechos, sino sólo la suspensión del cómputo de la prescripción. El principio de legalidad no parece ser una objeción igualmente concluyente en este ámbito.

La cuestión de si la prescripción de la acción penal o de la pena (ya impuesta) se sujeta al conjunto de garantías del nullum crimen nulla poena sine lege, es controvertida. Parte de la controversia consiste en la determinación del carácter sustantivo o procesal de la institución. En estos términos, si se afirma la "naturaleza" sustantiva de la prescripción, ésta queda sujeta al principio de legalidad, en tanto condición de la punibilidad. De lo contrario, en tanto mera condición de procesabilidad, la prescripción no quedaría cubierta por las consecuencias del principio de legalidad, al menos no con la misma intensidad. Bajo la tesis de "la conexión inmediata con el hecho como criterio de pertenencia al derecho material", Roxin afirma que la prescripción constituye un presupuesto de procesabilidad, y no de punibilidad, pues se trata de una circunstancia ajena al complejo del hecho, de modo que la garantía constitucional de la legalidad penal no se encuentra referida a ella ${ }^{32}$.

Lo anterior no obsta, sin embargo, a que el propio Roxin sostenga que el principio de legalidad impide la reapertura de los plazos de prescripción ya cumplidos,

pues al producirse la prescripción, el autor queda impune y puede confiar en ello [...]. Por eso, si posteriormente se considera como no producida la prescripción, ello supondría una posterior (re)fundamentación de la punibilidad, contraria al fin del art. 103 II GG33.

En caso de que el plazo de prescripción no se encuentre cumplido, sin embargo, Roxin entiende que una modificación retroactiva no puede entenderse constitucionalmente proscrita, pues entonces la protección de la confianza no se ve involucrada. Jakobs rechaza este punto de vista, en el entendido de que "el aspecto de confianza, de carácter psicológico, extravía hasta llegar a la suposición de que la prescripción no es objeto del principio de legalidad"34. Para Jakobs, la consideración fundamental se encuentra en que:

el Estado, al prorrogar el plazo de prescripción (o al establecer un cálculo de la prescripción que suponga prolongarla, o al facilitar la interrupción de la prescripción, etc.) amplía su competencia para punir, y ello, en la retroactividad deliberada, también bajo la impresión de hechos ya sucedidos, pero aún por enjuiciar ${ }^{35}$.

Desde el punto de vista mantenido por Jakobs, por ende, parece inviable la posibilidad de sostener que, respecto de los hechos respecto de los cuales se declare inaplicable el DL de amnistía, el plazo de prescripción no debería considerarse cumplido. Esta parecería ser la consecuencia de la concepción de la exigencia de legalidad como garantía de objetividad.

\footnotetext{
32 Roxin (C.), Derecho Penal Parte General, \$23, núm. 50-52.

33 Ibid $\ 5$ núm. 58. El artículo 103 II de la Ley Fundamental alemana (Grundgesets) establece el principio de legalidad penal.

${ }^{34}$ Jakobs (G.), Derecho Penal Parte General, Apartado 4 núm. 9.

35 Ibid.
} 
Mañalich - El secuestro como delito permanente ante el DL de amnistía

Debe destacarse que Jakobs ha profundizado este planteamiento en relación con un ámbito de casos que presenta una conexión relevante con el caso revisado por la Corte Suprema chilena: los homicidios en la frontera de la ex República Democrática Alemana. La conexión se expresa en la contraposición inicial que introduce Jakobs, a saber, la contraposición entre ilegalidad en el Estado y criminalidad de Estado:

La ilegalidad en el Estado es el desprecio de la relación jurídica que es constitutiva del Estado, como por ejemplo el homicidio culpable de un ciudadano por otro. Como crímenes de Estado se caracterizan aquí los actos de soberanía que dañan a una persona y que no pueden derivarse de la tarea de un estado moderno ${ }^{36}$.

Jakobs califica los homicidios de la frontera de la ex RDA de crímenes de Estado, y en tanto tales afirma su no-punibilidad, sobre la base de que conforme al derecho de la ex RDA esos hechos no eran punibles, por la existencia de una orden, dirigida a los tiradores, de disparar sin previo aviso si los prófugos alcanzaban los muros fronterizos. Por esto, bajo el derecho de la ex RDA vigente al momento de los hechos, los tiradores contaban con una causa de justificación. Frente a esto, Jakobs rechaza la posibilidad de abandonar la prohibición de retroactividad para así poder castigar esos homicidios (por la vía de negar ex post la causa de justificación), aun aceptando que a diferencia de lo que ocurre en "épocas homogéneas", en que la prohibición de retroactividad garantiza objetividad, en situaciones de ruptura revolucionaria:

su efecto es el contrario: vincula los nuevos tiempos a la arbitrariedad de los viejos, en este caso, a la permisión contraria a los derechos humanos de asesinar en la frontera a espionajes y a muchas, incluso prácticamente infinitas, cosas más ${ }^{37}$.

La razón para mantener la prohibición de retroactividad, empero, se encuentra en que la sujeción a la arbitrariedad del ordenamiento jurídico anterior resulta ser materialmente correcta, en el sentido de que:

si en el momento del hecho no existe la punibilidad, aunque su fundamento sea un mal fundamento, el hecho no puede caracterizarse como expresión de la maldad subjetiva, sino que en «este» ordenamiento aparece como adecuado, como normal ${ }^{38}$.

El argumento de Jakobs consiste en que, excluida la posibilidad de apelar a una fundamentación no positiva de una norma bajo la cual los hechos en cuestión fuesen ilícitos (por ejemplo, una apelación al derecho natural, inviable bajo un paradigma de derecho secular), debe aceptarse que esos hechos eran efectivamente lícitos bajo el derecho de la ex RDA, sin que quepa modificar retroactivamente este estatus.

Pese a que en principio hay buenas razones para calificar el secuestro de Miguel Angel Sandoval como un caso de criminalidad de Estado, el argumento de Jakobs no parece aplicable. Pues a menos que se acepte la tesis de los defensores en cuanto a que el

\footnotetext{
36 Jakobs (G.), “Crímenes del Estado-Ilegalidad en el Estado. ¿Penas para los homicidios en la frontera de la ex República Democrática Alemana?”, en Doxa, 17-18, 1995, p. 445.

37 Ibid 463.

38 Ibid 464
} 
artículo 10 del DL 5211974 establecía una autorización para realizar actuaciones semejantes, nada conduce a sostener que tales hechos no fuesen antijurídicos y punibles bajo el derecho chileno vigente al tiempo de su comisión.

Pero esta última aseveración no es una obviedad. Pues efectivamente el DL 521 establecía una autorización. La cuestión consiste en determinar qué era aquello que se autorizaba. Desde ya, debe decirse que el modo en que la Corte Suprema pretende fundamentar el rechazo de ese argumento de la defensa de los imputados es inaceptable. Según la Corte,

\begin{abstract}
el aludido artículo 10 del Decreto Ley $\mathrm{N}^{\circ}$ 521, invocado por la defensa de Godoy García es una disposición no publicada en el Diario Oficial, esto es, se trata lisa y llanamente de una norma secreta cuyo tenor se desconoce por la ciudadanía. Pero el artículo $6^{\circ}$ del Código Civil del Código Civil preceptúa que la ley no obliga sino una vez promulgada en conformidad a la Constitución Política del Estado y publicada de acuerdo a aquel ordenamiento; y el artículo $7^{\circ}$ del mismo cuerpo legal dispone que la publicación de la ley se hará mediante su inserción en el Diario Oficial, y ésta será su fecha, desde la cual se entenderá conocida de todos y será obligatoria. Aun cuando el Decreto Ley antes reseñado estableció normas diferentes sobre su publicación, los preceptos cuya publicación se omitió en caso alguno pueden considerarse como integrantes de nuestro régimen jurídico, por cuanto jamás han sido conocidos por la ciudadanía y, por lo tanto, no pueden esgrimirse para justificar la realización de conductas delictuales como aquellas desplegadas por el condenado, aunque fuese de los pocos conocedores de su contenido, máxime si se repara en su ilicitud (considerando 23).
\end{abstract}

Esta no puede ser la razón para negar la justificación de las acciones. Pues es obvio que una norma de rango legal puede alterar las condiciones para su entrada en vigencia establecidas en otra norma del mismo rango. De lo contrario, sería imposible la idea misma de derogación tácita. Por lo demás, para que una autorización (o una orden) pueda tener efecto justificante no parece en todo caso necesario que dicha autorización satisfaga las condiciones de promulgación y publicación de la ley.

Es mucho más relevante la consideración posterior de la Corte, en el sentido de que aun bajo las normas que autorizaban a los funcionarios a allanar y detener personas, la detención de la víctima en un centro clandestino, como lo era Villa Grimaldi, resultaba ilícita:

[...] Villa Grimaldi ni siquiera aparece entre los establecimientos de detención determinados más tarde por el Decreto Supremo $\mathrm{N}^{\circ}$ 146, del Ministerio del Interior, de diez de febrero de 1976 e incluso el gobierno de entonces negó su existencia [...] (considerando 24).

El derecho chileno vigente al momento de los hechos prohibía y conminaba penalmente la comisión de esos hechos. En este sentido, por ende, no se trata de la modificación retroactiva del estatus deóntico de los hechos. Sólo se trata de una determinación del momento a partir del cual debe computarse el plazo de prescripción de la acción penal, la cual, sin embargo, parecería desafiar el tenor literal del artículo 95 del Código Penal: "El término de la prescripción empieza a correr desde el día en que se hubiere cometido el delito". ¿Constituiría esto una infracción del principio de legalidad 
Mañalich - El secuestro como delito permanente ante el DL de amnistía

como garantía de objetividad? Esto no puede resolverse sin considerar reflexivamente la institución de la prescripción.

Son usuales explicaciones del fundamento de la prescripción que se centran en su vinculación a los distintos fines que se asigna a la pena. Así, por ejemplo, Maurach sostiene que:

El transcurso del tiempo morigera la necesidad de expiación de los miembros de la colectividad jurídica, siempre limitada en el tiempo en alguna medida, hasta extinguirla; por ello, en tales casos, la pena cesa en su función de afianzamiento jurídico relativo, psicológico [...] Del mismo modo, también es posible que las necesidades de prevención especial concurrentes frente a un hecho flagrante, puedan decaer o incluso errar su meta: quien resulta condenado por un hecho ocurrido hace largo tiempo y olvidado, siente, como entregado al nudum ius, no intimidación, sino amargura ${ }^{39}$.

Si se rechaza una explicación psicologizante de la función de la pena, esto es, si se mantiene una concepción comunicativa de la función de la pena, y se vincula ésta al significado ilocucionario de restablecimiento de la vigencia de la norma defraudada, y no a sus (siempre contingentes) efectos perlocucionarios, entonces esta explicación del fundamento de la prescripción no es plausible. Pero esto no significa que no haya buenas razones detrás de la institución de la prescripción. El establecimiento de la prescripción de la acción penal y de la pena como causa de extinción de la responsabilidad penal puede entenderse como un compromiso del Estado de derecho. En la persecución punitiva, el Estado se somete a restricciones, que en este caso son de carácter cronológico. Transcurrido un espacio de tiempo más o menos prolongado, según cuál sea la gravedad del delito, sin que la persecución se concrete en la imposición o en la ejecución de la pena, el Estado abandona la persecución. El Estado de derecho no mantiene indefinidamente abierta la contingencia de la punición. De ahí que sea problemática la legitimidad de las normas de derecho internacional que establecen la imprescriptibilidad de (la persecución penal de) determinados delitos ${ }^{40}$.

Si lo anterior es correcto, aparece una razón que justifica la negación de la prescripción de la acción penal relativa a los hechos respecto de los cuales se ha fundamento la posibilidad de inaplicar el DL de amnistía. Lo que el Estado de derecho no autoriza es el mantenimiento indefinido de la contingencia de la punición. Esto presupone, sin embargo, que la punición sí ha sido contingente por algún espacio de tiempo. Pero esto es precisamente lo que no ocurre en relación con los delitos de impunidad, al menos en el sentido en que aquí se los entiende. Lo constitutivo de los delitos de impunidad es la supresión institucional de la contingencia de la punición. En ellos no se trata del posicionamiento estratégico del ciudadano frente a la potestad punitiva del Estado, en términos de lograr eludir su ejercicio dentro del lapso que el Estado de derecho se concede a sí mismo para materializar la imputación. En los delitos de impunidad, se trata del posicionamiento estratégico desde el ejercicio del poder estatal. Un delito cubierto por una auto-amnistía es un delito respecto del cual la punición no es

\footnotetext{
${ }^{39}$ Maurach, Gössel, Zipf, Derecho Penal Parte General, Tomo II, Astrea, Buenos Aires, 1995, \ 75, núm. 13.

${ }^{40} \mathrm{El}$ artículo 29 del Estatuto de Roma establece la imprescriptibilidad de los crímenes que son objeto de la competencia de la Corte. El artículo VII de la Convención sobre Desaparición Forzada de Personas dispone lo mismo para el delito de desaparición forzada de personas.
} 
REJ - Revista de Estudios de la Justicia - No 5 - Año 2004

contingente, sino imposible. O sea, es un delito respecto del cual la no-punición es necesaria. De nuevo, esto satisface el significado de "impunidad". Respecto de estos delitos, la prescripción no puede correr sino una vez que la punición se vuelve contingente. Pero esto sólo puede alcanzar a aquellos cuya responsabilidad no se ha extinguido por otra razón, incluida la (hetero-)amnistía. 